\title{
Motion - Computerized tomographic colography is a better method for screening for polyps: Arguments against the motion
}

\author{
Jerome B Simon MD FRCPC
}

\begin{abstract}
JB Simon. M otion - C omputerized tomographic colography is a better method for screening for polyps: A rguments against the motion. C an J G astroenterol 2003;17(2):129-131.

Computerized tomographic (CT) colography is an exciting technique whereby images of the colonic wall and lumen can be obtained without col onoscopy. It is not as good as conventional colonoscopy, however, because of both inherent and performance limitations. A mong the former is the inability to visualize subtle mucosal lesions, such as alterations in colour or pliability. M ore importantly, CT colography is strictly a diagnostic technique, and does not allow biopsy or removal of polyps. The vigorous bowel preparation required for this procedure can be very unpleasant for the patient, and includes purgatives followed by distension of the colon with air. Unlike with colonoscopy, adherent stool can be difficult to distinguish radiologically from polyps or cancers; as a result, many patients require colonoscopy anyway. The major performance limitations of CT colography are poor sensitivity and specificity compared with conventional colonoscopy. Rectal lesions, flat adenomas and diminutive adenomas are especially difficult to detect, and false-positive results are also common. In addition, the procedure is expensive and less cost effective than colonoscopy. CT colography takes relatively little patient time, but a substantial amount of time is needed for the radiologist to interpret the images. Interobserver variability is high. For all of these reasons, CT colography cannot be recommended as a screening test for colorectal neoplasia.
\end{abstract}

Key W ords: Colonoscopy; C T colography; Polyp surveillance

\section{M otion - La colographie par tomodensitométrie est une meilleure méthode de dépistage des polypes : A rguments contre la motion}

\begin{abstract}
La colographie par tomodensitométrie est une technique intéressante selon laquelle il est possible d'obtenir des images de la paroi et de la lumière du côlon sans coloscopie. Cependant, elle n'est pas aussi efficace que la coloscopie traditionnelle en raison de limites inhérentes et de rendement. Parmi les limites inhérentes, soulignons l'incapacité de visualiser de subtiles lésions muqueuses, comme des altérations de la couleur ou de la souplesse. $M$ ais avant tout, la colographie par tomodensitométrie est une technique strictement diagnostique qui ne permet pas d'effectuer une biopsie ou d'exciser des polypes. La préparation vigoureuse de l'intestin nécessaire pour cette intervention peut se révéler très déplaisante pour le patient, car elle inclut la prise de purgatifs et une distension du côlon avec de l'air. Contrairement à ce qui est le cas avec la coloscopie, il peut être difficile de distinguer à la radiologie les adhérences fécales des polypes ou des lésions cancéreuses. Par conséquent, de nombreux patients doivent tout de même subir une coloscopie. La principale limite de rendement de la colographie par tomodensitométrie est une mauvaise sensibilité et une mauvaise spécificité par rapport à la coloscopie traditionnelle. Les lésions rectales, les adénomes plats et les adénomes minimes sont particulièrement difficiles à déceler, et les faux résultats positifs sont également monnaie courante. De plus, l'intervention est coûteuse et moins rentable que la coloscopie. La colographie par tomodensitométrie prend relativement peu de temps pour le patient, mais le radiologue doit consacrer beaucoup de temps à interpréter les images. La variabilité est élevée entre les observateurs. Pour toutes ces raisons, la colographie par tomodensitométrie ne peut être recommandée comme test de dépistage d'une néoplasie colorectale.
\end{abstract}

$\mathrm{T}$ he advent of computerized tomographic (CT) colography ('virtual colonoscopy') in 1994 represented an exciting new concept in the evaluation of the colon: the bowel could be searched for cancers and polyps without colonoscopic intrusion. W ith this technique, spiral CT images of the colon are obtained after the bowel is cleansed and distended with air. The radiologist later analyzes the computerized representations of the colonic lumen and wall. Ongoing technical advances have led to improvements in 2- and 3-dimensional visualization of the colonic lumen, along with impressive virtual 'flythroughs' that simulate a colonoscopic procedure. Radiologists and other enthusiasts boast of the minimally intrusive nature of the examination, claim that it is as effective (or nearly so) as colonoscopy in detecting neoplasia, and predict its widespread use as a tool for colorectal screening of the general population (1-4).

$\mathrm{H}$ igh-tech radiology is indeed exciting, but is $\mathrm{CT}$ colography really as good as colonoscopy? Do its advantages outweigh its limitations and weaknesses? Could it replace colonoscopy as the gold-standard screening test for polyps? I think that the answer to each of these questions is a clear ' $\mathrm{N} 0$ !'.

The problems with this procedure fall into two major categories:

- inherent limitations

- performance limitations, which are potentially amenable to technical improvements

This article was originally presented at a symposium entitled, "C ontroversies in G astroenterology", sponsored by A xcan Pharma, Toronto, 0 ntario, A pril 8 to 10, 2002

Division of $\mathrm{G}$ astroenterology, $\mathrm{H}$ otel Dieu H ospital, K ingston, $\mathrm{O}$ ntario

C orrespondence and reprints: Dr Jerome B Simon, D ivision of G astroenterology, H otel Dieu H ospital, 166 Brock Street, K ingston, 0 ntario

K7L 5G 2. Telephone 613-544-3400 ext 2483, fax 613-544-3114, e-mail simonj@post.queensu.ca 


\section{IN HERENT LIMITATION S}

The very name, 'virtual colonoscopy', illustrates a fundamental limitation of the test - it provides a 'virtual' scan of the colon, not a 'real' one. A s interesting as the computer images might be, they can never replace the magic of nature's actual living, breathing bowel that the endoscopist sees. Subtleties of colouration and pliability, among other attributes of the mucosa, are of great diagnostic value and are readily observed at colonoscopy, but escape the sterile, fixed grayness of the C T scan's eye.

Even more importantly, traditional colonoscopy has the enormous advantage of being therapeutic as well as diagnostic for polyps. Lesions detected at CT colography are mere shadows; they require subsequent colonoscopy for confirmation and biopsy and/or removal. A related, but separate, limitation is the lack of capacity to acquire tissue. Colonoscopists can biopsy subtle irregularities that evade detection by $\mathrm{CT}$ colography.

CT colography is not as 'minimally invasive' as its proponents claim. Patients require the same type of thorough bowel preparation as for colonoscopy, which many subjects find extremely uncomfortable and more traumatic than the endoscopic procedure itself. Furthermore, immediately before the examination, a rectal tube is inserted, through which air is insufflated 'to maximum patient tolerance' $(2,4)$. In many centres, this is followed by an intravenous injection of an antispasmodic agent, such as Buscopan (Boehringer Ingelheim, Ontario) or glucagon, to maximize bowel distension. In a recent study in which both procedures were explained to patients, only $60 \%$ of subjects preferred CT colography for colorectal screening; the other $40 \%$ either preferred colonoscopy or expressed no preference (5). In another recent study, patients who underwent both procedures reported more discomfort or pain with CT colography than with conventional colonoscopy, and significantly more patients preferred the latter procedure (6). A s one wag pointed out:

“... from the patient's point of view, virtual colonoscopy will not be perceived as a major advance unless or until it can be preceded by a virtual bowel preparation, in which virtual GoLytely is used." (7)

A thorough bowel preparation is important for colonoscopy, but is absolutely crucial for a successful CT colographic examination. A $n$ endoscopist can easily distinguish between adherent stool and a tumour, but a radiologist often cannot. A nything less than pristine cleanliness results in a high frequency of false-positive interpretations. In such cases, the unfortunate patient is needlessly subjected to a subsequent colonoscopy to confirm the findings.

Because of the presence of a tube for air insufflation, rectal lesions are easily missed at CT colography.

\section{PERFORMANCE LIMITATIONS}

CT colography is an evolving technology and performance characteristics will undoubtedly improve with increasing experience. Currently, however, there are major limitations and weaknesses with this technique compared with colonoscopy.

\section{Sensitivity}

Some authors report that CT colography is able to detect about $90 \%$ of colonic cancers and polyps larger than $1 \mathrm{~cm}$ in diameter that have been identified at colonoscopy $(2,4,8)$. 0 ther papers published in the past two years, however, have described disappointingly low sensitivities for large polyps, from only $38 \%$ to $73 \%(9,10)$. Even in one study that found $90 \%$ sensitivity for large polyps, a $2.5 \mathrm{~cm}$ neoplasm was overlooked (2). Flat aden omas are especially likely to be missed by CT colography (11-13), an event that rarely occurs with conventional colonoscopy $(14,15)$.

CT colography is much less able than conventional colonoscopy to detect smaller polyps. The most optimistic investigators report sensitivities of approximately $80 \%$ for polyps $5 \mathrm{~mm}$ to $9 \mathrm{~mm}$ in diameter and $55 \%$ to $60 \%$ for smaller lesions $(2,4)$, but most studies have yielded far lower values $(8,10,12)$. Proponents of this technique argue that polyps of less than $1 \mathrm{~cm}$ diameter are not clinical ly important, but this is only partly true. A significant, al beit small, proportion of small adenomas harbour high-grade dysplasia or even frank malignancy. M oreover, small lesions can grow into larger ones that have greater malignant potential.

\section{Specificity}

The false-positive rates with $\mathrm{CT}$ colography are far too high. M ost investigators have reported specificities of only $60 \%$ to $80 \%$, if they mention them at all $(2,4,8,9)$. Even for lesions larger than $1 \mathrm{~cm}$ in diameter, specificities are only $80 \%$ to $90 \%$ $(2,9)$. This poses a major problem that CT enthusiasts rarely discuss, which is the high proportion of subjects who require subsequent colonoscopy because of the erroneous identification of lesions at CT colography.

Improved bowel preparation and other technical advances might ultimately enhance the specificity of this technique, but false-positive results will always be an important limitation. This is especially important when one considers screening of the general population, in which high specificity is critical to make the program cost effective.

\section{Cost effectiveness}

The actual costs of CT colography are impossible to glean from the literature, but it is clearly an expensive procedure. Even disregarding the very high capital expenditures for the equipment, it is unlikely that CT colography will ever approach colonoscopy in cost effectiveness. M arkov modelling has shown that colonoscopic screening would still be more cost effective even if the sensitivity and specificity of CT colography were both $100 \%(16)$. The imaging technique could compete with colonoscopy only if compliance rates were higher by $15 \%$ to $20 \%$ and procedure costs were lower by more than half (16).

\section{0 ther performance weaknesses}

Studies of CT colography have all involved patients with suspected colonic lesions or risk factors for colonic disease. The sensitivity and specificity of this technique in a more realistic screening situation have not yet been assessed, but almost certainly would be substantially lower than figures quoted in the reported literature.

Proponents of CT colography emphasize the much shorter procedural time compared with colonoscopy. Though this is a major benefit for the patient, the radiologist needs a substantial amount of time (typically half an hour or more) to view 
and interpret the computer images after the patient leaves. This is a serious limitation to the use of CT colography as a screening tool.

Finally, there is limited interobserver reproducibility for C T colography, even among experienced radiologists, which leads to marked variations in its sensitivity and specificity (9).

\section{CONCLUSIONS}

CT colography is a remarkable and fascinating technique, but its sensitivity, specificity and cost effectiveness are inferior to those achieved with colonoscopy. Even if technical advances were to minimize these problems, inherent limitations of the procedure - especially the inability to take biopsies or effect therapy - would still make it inferior to conventional colonoscopy as a screening test for colorectal neoplasia.

\section{REFERENCES}

1. Johnson CD, Dachman A H. CT colonography: The next colon screening examination? Radiology 2000;216:331-41.

2. Fenlon H M, N unes DP, Schroy PC 3rd, Barish MA, Clarke PD, Ferrucci JT. A comparison of virtual and conventional colonoscopy for the detection of colorectal polyps. N Engl J M ed 1999;341:1496-503.

3. Halligan S, Fenlon H M . Virtual colonoscopy. BM J 1999:319:1249-52.

4. Yee J, A kerkar GA, H ung RK, Steinauer-G ebauer A M , W all SD, $M$ cQ uaid KR. C olorectal neoplasia: Performance characteristics of CT colonography for detection in 300 patients. Radiology 2001;219:685-92.

5. A ngtuaco TL, Banaad-O miotek GD, H owden CW. Differing attitudes toward virtual and conventional colonoscopy for colorectal cancer screening: Surveys among primary care physicians and potential patients. A m J Gastroenterol 2001;96:887-93.

6. A kerkar GA, Yee J, H ung R, M cQ uaid K. Patient experience and preferences toward colon cancer screening: A comparison of virtual colonoscopy and conventional colonoscopy. G astrointest Endosc 2001;54:310-5

7. Silverman C. Virtual colonoscopy. N Engl J M ed 2000;342:738. (Lett)

8. Kay CL, Kulling D, H awes RH, Young JW, Cotton PB. Virtual endoscopy - comparison with colonoscopy in the detection of space-occupying lesions of the colon. Endoscopy 2000;32:226-32.

9. Pescatore P, G lücker T, D elarive J, et al. Diagnostic accuracy and interobserver agreement of CT colonography (virtual colonoscopy). G ut 2000;47:126-30.

10. M endelson RM, Foster N M, Edwards JT, Wood CJ, Rosenberg M S, Forbes G M . Virtual colonoscopy compared with conventional colonoscopy: A developing technology. M ed J A ust 2000;173:472-5.

11. Hara A K, Johnson CD, Reed JE, et al. Detection of colorectal polyps with CT colography: Initial assessment of sensitivity and specificity. Radiology 1997;205:59-65.

12. Rex DK, Vining D, Kopecky KK. A n initial experience with screening for colon polyps using spiral CT with and without CT colography (virtual colonoscopy). G astrointest Endosc 1999;50:309-13.

13. Spinzi G, Belloni G, M artegani A, Sangiovanni A, Del Favero C, M inoli G. Computed tomographic colonography and conventional colonoscopy for colon diseases: A prospective, blinded study. A m J Gastroenterol 2001;96:394-400.

14. Hixson LJ, Fennerty M B, Sampliner RE, G arewal HS. Prospective blinded trial of the colonoscopic miss-rate of large colorectal polyps. Gastrointest Endosc 1991;37:125-7.

15. Rex DK, Cutler CS, Lemmel GT, et al. Colonoscopic miss rates of adenomas determined by back-to-back colonoscopies. Gastroenterology 1997;112:24-8.

16. Sonnenberg A, Delcò F, Bauerfeind P. Is virtual colonoscopy a costeffective option to screen for colorectal cancer? A m J Gastroenterol 1999;94:2268-74. 


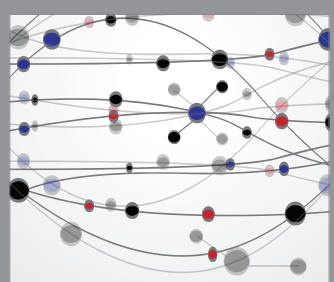

The Scientific World Journal
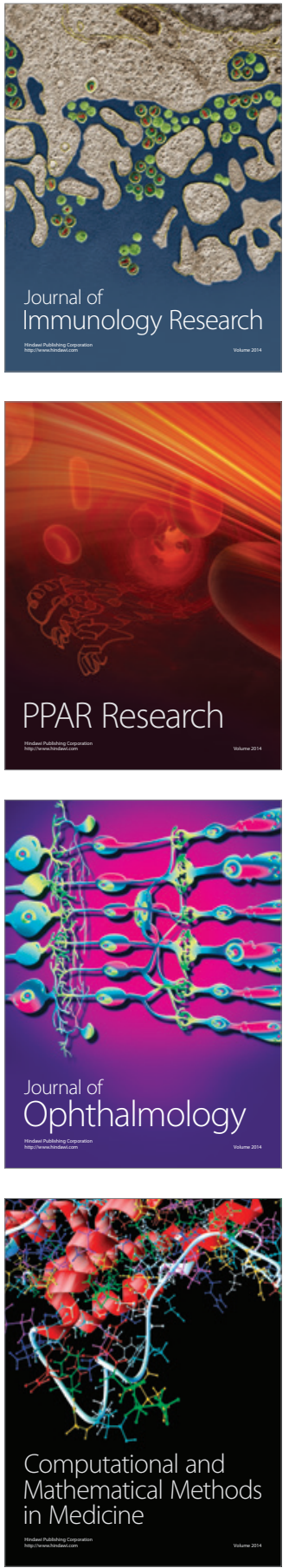

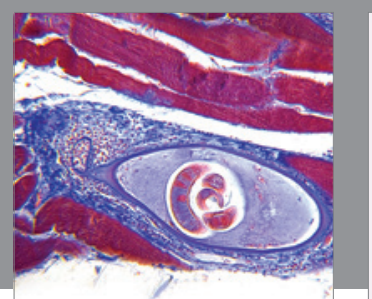

Gastroenterology Research and Practice

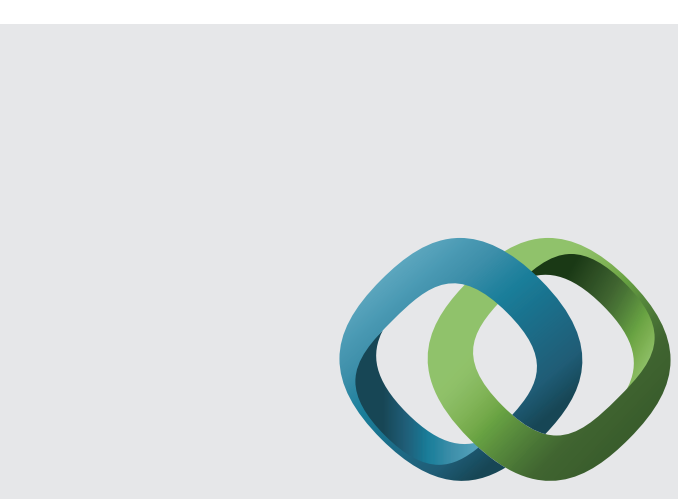

\section{Hindawi}

Submit your manuscripts at

http://www.hindawi.com
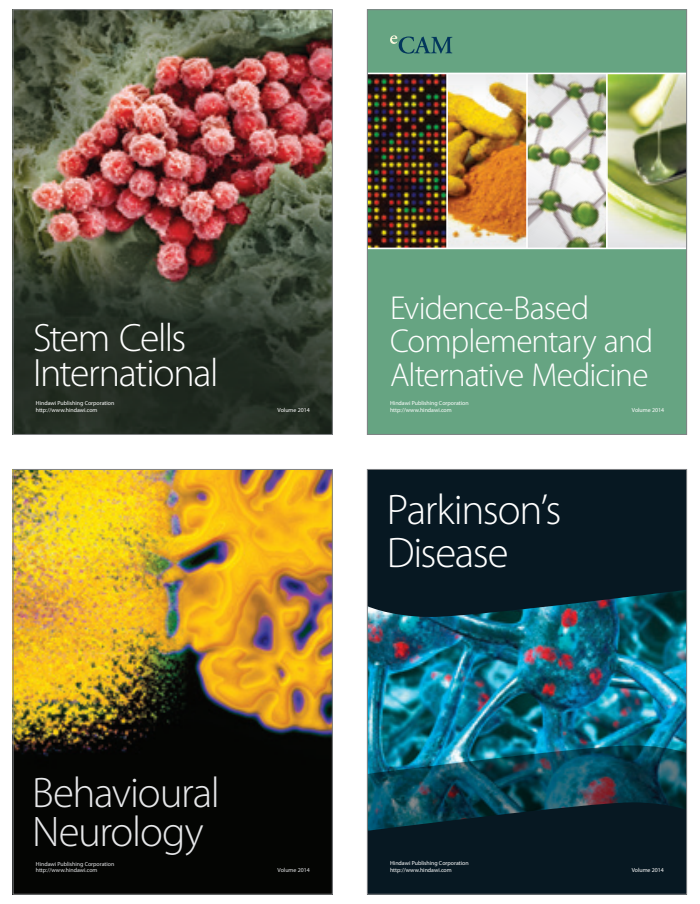
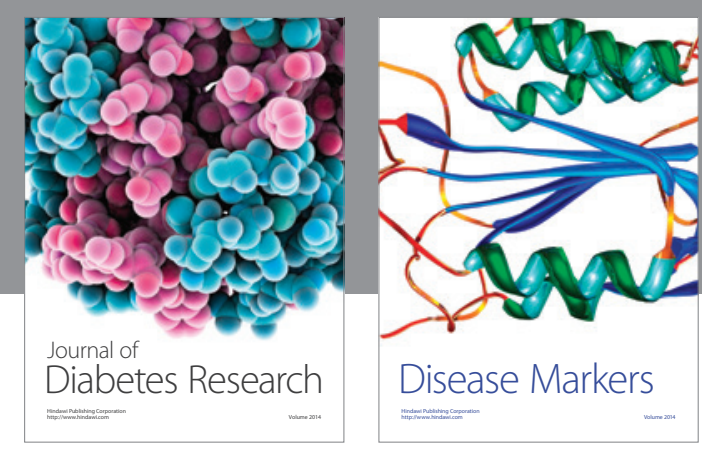

Disease Markers
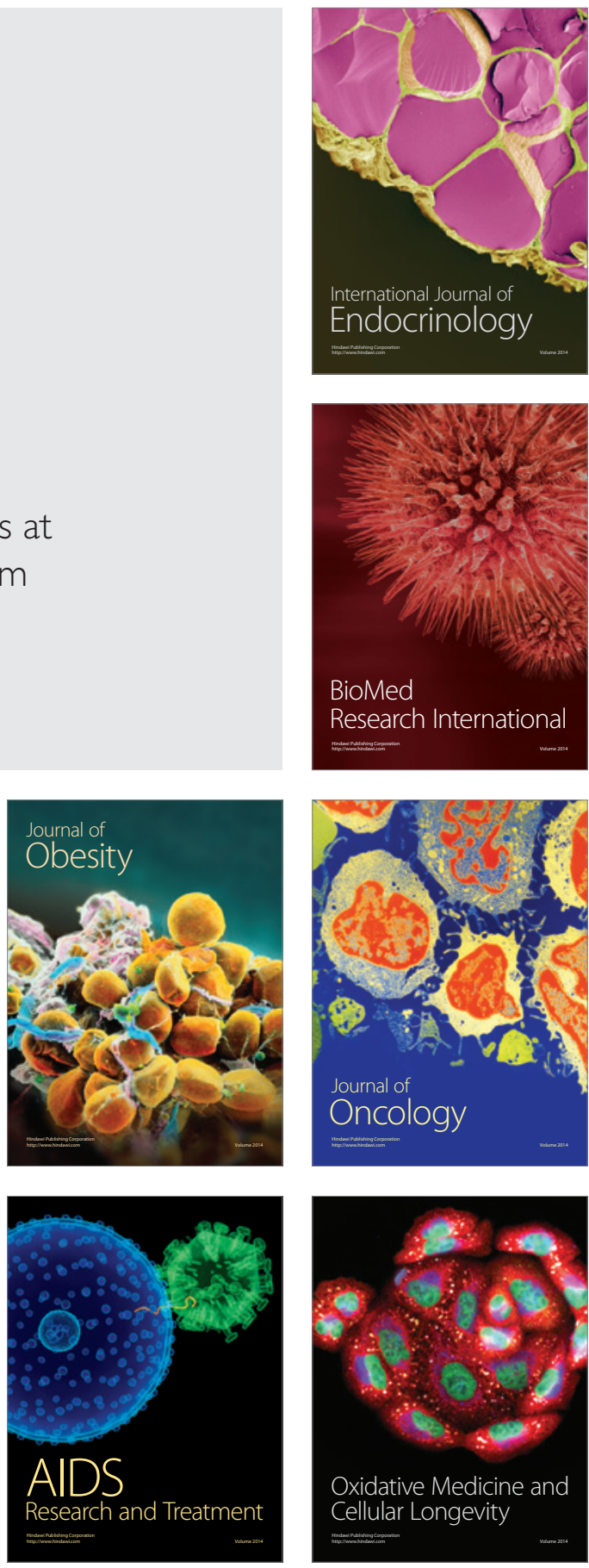